\title{
Discharge Curve Analysis of a Lead-Acid Battery Model
}

\author{
José H. F. Viana', Juliana O. Costa ${ }^{1}$, Iago C. Nilson', David C. C. Freitas', Hugerles S. Silva ${ }^{2}$ \\ Federal Institute of Mato Grosso - Primavera do Leste ${ }^{1}$, Federal University of Campina Grande ${ }^{2}$ \\ jhenrique.fontaniva@gmail.com, julianaottonelli@ outlook.com, i.c.nilson@gmail.com, \\ david.freitas@pdl.ifmt.edu.br, hugerles.silva@ee.ufcg.edu.br
}

\begin{abstract}
Battery technologies are presented. Then the battery models are classified into three types: electrochemical, based on electrical circuits and analytical models. A model is chosen for research. The form of parameter identification is presented. Some points of the discharge curve are required and it is performed computer simulations in which is found the best degree for polynomial interpolation. It is performed the analysis of similarities between interpolation and battery model. The results are presented from the analyzes, comparing the interpolation with the equation proposed by Tremblay (2007).
\end{abstract}

Keywords: Battery Models, Lead Acid Battery, Parameter Estimation.

\section{INTRODUCTION}

Electricity is currently the most widely used form of energy in the world. It is present in basically everything, being essential to the current society. The need and dependence on energy is increasing and becoming even more important for the population [1]. In this way, failures or losses of this energy are not tolerated, because this causes enormous damages. As a result, the use of batteries increases. Battery technologies are increasingly advancing. These, dating from the 19th century, created by Alessandro Volta and perfected in 1859 by Gaston Plantê, are used in the form of battery banks to overcome these failures and losses during consumption in the network provided by the companies [2]. The most used are [3]:

\section{A) Nickel-Cadmium}

Battery technology that uses chemical elements harmful to the environment and has been losing sales due to short life (memory effect, in which the battery loses some of its storage capacity during each load).

\section{B) Lithium Ion}

They are widely used in electronics and gadgets, because of the safety they have. On the other hand, because they are expensive, it becomes unfeasible on a large scale.

\section{C) Lead-Acid}

This type of battery uses the chemical reaction between lead and sulfuric acid to generate electricity. Lead-acid batteries are widely consumed in the automotive industry, as a source of energy in automotive vehicles, and also in largescale systems such as electric power supply. For these main reasons, the lead- acid battery is the type of battery to be studied and improved, since it can supply large-scale faults.

One of the subjects to be studied and improved in the area of lead-acid batteries is their charge and discharge cycles. Using charge and discharge cycles, it's possible to estimate some electrical characteristics of this battery. There is a need to use techniques to estimate the electrical characteristics of the batteries. In this way, the battery models try to simulate the actual operational characteristics and can be used to predict their behavior under various charging and discharging cycles [4].

These models are useful tools for systems that use batteries because they allow an analysis of their behavior in different design specifications [5]. Battery models are very important for the analysis, since an uncertainty associated with its useful life affects the cost of the energy generated by that system and the replacement of a damaged battery could be carried out before large losses [6].

\section{BATTERY MODELS CLASSIFICATION}

There are several models to represent the charge and discharge of batteries, which we use to characterize the reality of what happens during its use and thus have a forecast of lifetime, SOC (state of charge) and voltage. For this, we classify these models into three types, with different complexities [5]:

\section{A) Electrochemical models}

They are models that use, as expressed in the name, electrochemical characteristics of the battery, such as mass transport characteristics, thermodynamic, electrical and thermal properties of the materials used and simulate these with great 
detail in a large number of parameters. Therefore, they are more complex than the other models, and therefore are more accurate and difficult to implement [7].

\section{B) Based on electrical circuits models}

They are based on electrical circuits and take into account variable loads, capacity rate and thermal effects of the battery. For this purpose, for example, voltage and current sources, resistors, capacitors and inductors are used. These models are considered to be of less complexity than the electrochemical [8], [9], [10].

\section{C) Analytical models}

For these models, which describe the battery in an abstract way, we use interpolation and extrapolation of data obtained in the field through the experimental part and in tests of the manufacturer. In this way, they are considered to be easy to use in relation to electrochemicals and based on electrical circuits and can be configured for different battery types, besides having an extremely lower computational cost than the electrochemical ones [11], [12], [13], [14], [15].

For this study, one of these models was chosen, formulated by [15], in order to observe the estimation of the discharge of a constant current commercial battery by means of data interpolations.

\section{BATTERY MODEL}

An analytical model was proposed and it can be used to discharge the battery, where it aimed that in a battery with non- linear voltage that own voltage would depend exclusively on the battery charge. Thus, when the battery is fully discharged and there is no current flow, the voltage approaches $0 \mathrm{~V}[15]$.

Figure 1 represents the behavior of the system proposed by [15], where the discharge voltage depends on the current applied. In this way, the discharge equation is given by (1):

$$
v(t)=E O-K Q /(Q-i T)-R i+A e^{\wedge}(-B i T)
$$

In equation (1), all variables represented in lowercase letters, $v, i, i T$ are time dependent. The parameters and variables used in these two equations are: $v(t)$ is the battery voltage; $E O$ is the internal battery voltage; $K$ is the polarization constant; $Q$ is the nominal battery capacity; $i T$ is the actual consumed charge; $R$ is the internal resistance; $i$ is the discharging and/or charging curren and $A$ and $B$ are constants.

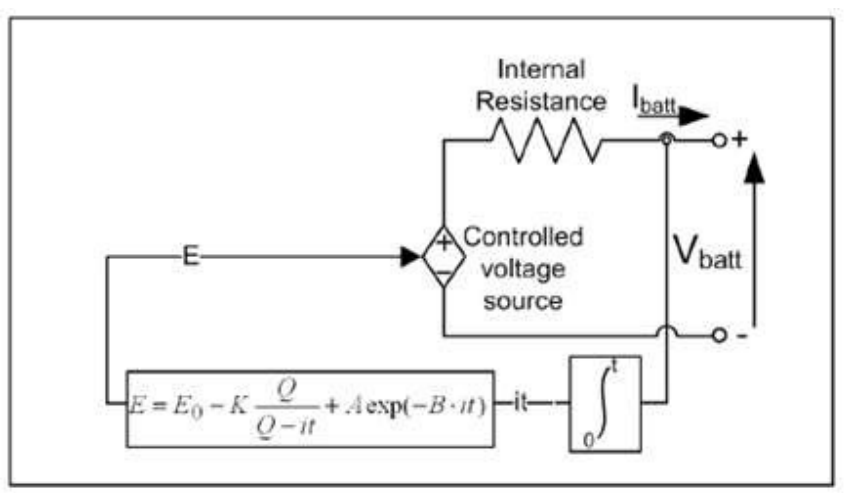

Figure 1: Battery charging discharging system by Tremblay et al. (2007), with a voltage source controlled in series with an internal resistance (Freitas, 2016)

\section{A) Parameter estimation}

According to [15], for the estimation of the parameters three points of the discharge curve are required as in Figure 2: full charge voltage Vfull, voltage at the end of the exponential zone Vexp and the nominal voltage at the final decay of the discharge curve Vnom. The above image was taken from [16] e [17].

After the established voltage values the next step is to propose three points in the battery discharge curve. These points must be chosen from a constant current and multiplied by the time in each desired zone. As shown in Figure 2, the first point is obtained at the beginning of the decay curve where time is zero because it is the start of current application for the discharge of the battery, so the initial charge will always be zero. In the same way, the exponential time texp at the end of the exponential zone is estimated and multiplied by the constant current of the battery, thus establishing the exponential load Qexp. Finally, the nominal time tnom resulting from the final decay of the discharge curve is

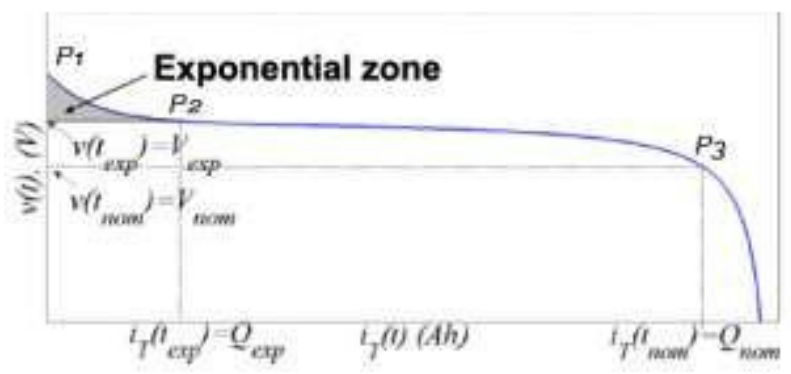

estimated.

Figure 2: Representation of a characteristics discharge of a battery with three points proposed by Tremblay model to obtain the parameters (Freitas, 2016).

According to Tremblay et al. (2007), the parameters $A, B$, $K$ and $E O$ are obtained by the following equations: 


$$
\begin{aligned}
& A=\text { Vfull }- \text { Vexp } \\
& B=3 / \text { exp } \\
& K=\left(\text { Vfull-Vnom }+A\left(e^{\wedge}(-B \text { Qnom-1 })\right)(\text { Q-Qnom }) /\right. \text { Qnom }
\end{aligned}
$$

$$
E O=\text { Vfull }+K+R i-A
$$

In equations (2) to (5) the parameters and variables used in these two equations are: $A$ is the amplitude of the exponential zone; Vfull is the fully charged battery voltage; $V \exp$ is the voltage of the battery just after the exponential zone; $B$ is the inverse time charge constant of the exponential zone; Qexp is the capacity of the battery after the exponential zone; $K$ is the polarization voltage, Vnom is the battery voltage just after the nominal zone; Qnom is the capacity of the battery after the nominal zone; $E O$ is the constant voltage of the battery; $R$ is the internal resistance of the battery and $i$ is the battery current.

\section{PARAMETRIZATION AND POLYNOMIAL INTERPOLATION}

Using computer simulation software, the data estimation analysis was performed from the discharge curve shown in Figure 3, at the constant current of 2.5A. As proposed by [15], the voltage depends on the current supplied, and it influences the discharge time of the battery.

According to the equation, three points of the discharge curve are required to calculate the parameters. For this, different nominal voltages Vnom were used, with time $t$ of 10, 11 and 12 hours. The curve points for the three different times P310, P311 and P312 were defined as shown in tables 1 and 2 .

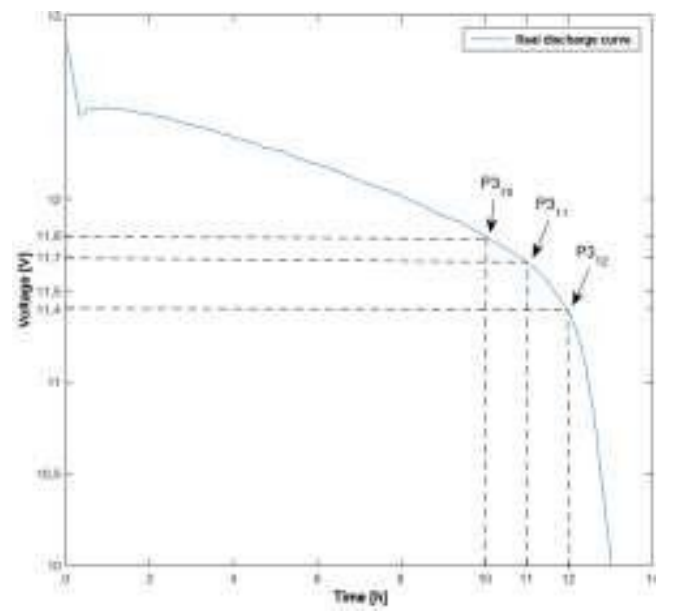

Figure 3: Commercial battery discharge curve used at constant current of $2.5 \mathrm{~A}$
Table 1: Values of the parameters at the points of the discharge curve used

\begin{tabular}{|c|c|}
\hline Parameter & Values \\
\hline Vfull & $12.8 \mathrm{~V}$ \\
\hline Vexp & $12.6 \mathrm{~V}$ \\
\hline Vnom10 & $11.8 \mathrm{~V}$ \\
\hline Vnom11 & $11.7 \mathrm{~V}$ \\
\hline Vnom12 & $11.4 \mathrm{~V}$ \\
\hline Qfull & $36 \mathrm{Ah}$ \\
\hline Qexp & $1.25 \mathrm{Ah}$ \\
\hline Qnom10 & $25 \mathrm{Ah}$ \\
\hline Qnom11 & $27.5 \mathrm{Ah}$ \\
\hline Qnom12 & $30 \mathrm{Ah}$ \\
\hline
\end{tabular}

Table 2: Values of the points of the discharge curve used

\begin{tabular}{|c|c|}
\hline Points & Values \\
\hline$P 1$ & $(0 \mathrm{Ah}, 12.8 \mathrm{~V})$ \\
\hline$P 2$ & $(1.25 \mathrm{Ah}$, \\
\hline$P 310$ & $(25 \mathrm{Ah}, 11.8 \mathrm{~V})$ \\
\hline$P 311$ & $(27.5 \mathrm{Ah}$, \\
\hline$P 312$ & (30Ah, 11.4V) \\
\hline
\end{tabular}

The parameters were defined as presented in Table 3 and calculated according to the values for the three points of $P 3$.

Table 3: Values of the points of the discharge curve used

\begin{tabular}{|c|c|}
\hline Parameter & Values \\
\hline$A$ & $0.2 \mathrm{~V}$ \\
\hline$B$ & $2.4 \mathrm{Ah}^{\wedge}(-$ \\
\hline$K 10$ hours & $0.2640 \mathrm{~V}$ \\
\hline$E 010$ hours & $12.8885 \mathrm{~V}$ \\
\hline$K 11$ hours & $0.1854 \mathrm{~V}$ \\
\hline$E 011$ hours & $12.8099 \mathrm{~V}$ \\
\hline$K 12$ hours & $0.12 \mathrm{~V}$ \\
\hline$E 012$ hours & $12.7445 \mathrm{~V}$ \\
\hline
\end{tabular}

Note that there is a large divergence between the curves estimated by the parameters with the change in Vnom, as shown in Figure 4. Thus, by analyzing the three discharge curves and comparing with the original curve of the commercial battery, the nominal voltage at 10 hours is closer to the voltage presented by the commercial battery, as shown in more detail in Figure 5.

With these data already established from the real curve of Figure 3, the interpolation between ten different polynomial degrees was performed, as shown in Figure 6. The Lagrange polynomial, presented in equation (6), was taken as the basis for 
the purpose of defining and indicating, among the interpolated curves, the one that best fits the estimation of the discharge curve.

$$
v(j)=\Sigma \_\{j=0\}^{\wedge}\{n\} p(j+1) t(j)^{\wedge}(n-(j+1))
$$

In equation (6), the parameters and variables used in this equation are: $j$ is the polynomial variation of time; $v(j)$ is the time- dependent interpolation voltage; $p$ is the polynomial; $t(j)$ is the discharge time of the battery and $n$ is the polynomial degree. Each degree of interpolation has a relative error estimated by the interpolated polynomial equation, as shown in Figure 7, which is used in choosing the best polynomial degree. This is represented by equation (7).

$$
E(j)=(v(j)-x(j)) / x(j)
$$

In equation (7), the parameters and variables used in this equation are: $E(j)$ is the interpolation error; $v(j)$ is the interpolation voltage and $x(j)$ is the voltage of the battery discharge curve.

Based on the relative errors presented in Figure 7, the mean squared error MSE of each curve is calculated. The computational simulation is performed to obtain the data processing time, in which the data of the original curve the curve interpolation and the associated MSE were contained in its algorithms for each polynomial degree. Table 4 presents the data of the simulations that were executed in a computer system with $1.70 \mathrm{GHz}$ Intel Core i3 processor, using a 64bit operating system.

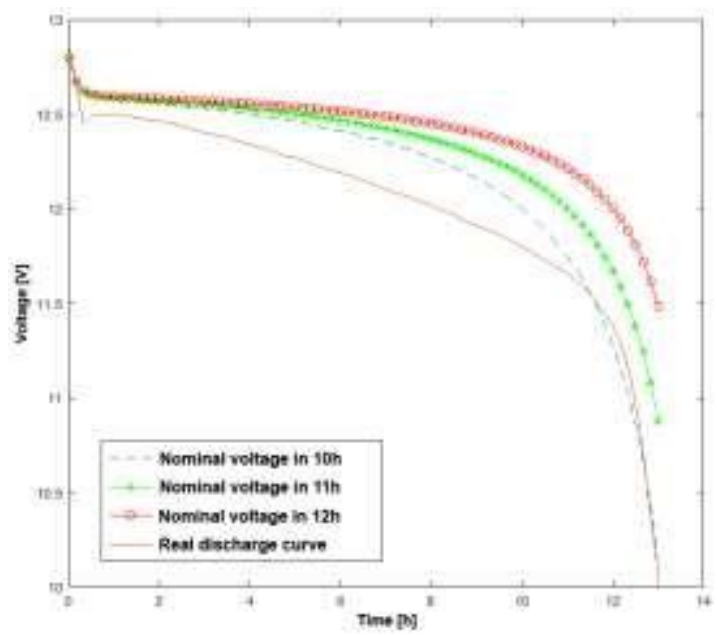

Figure 4: Comparison between the curves estimated by the parameters and the original discharge curve of the commercial battery

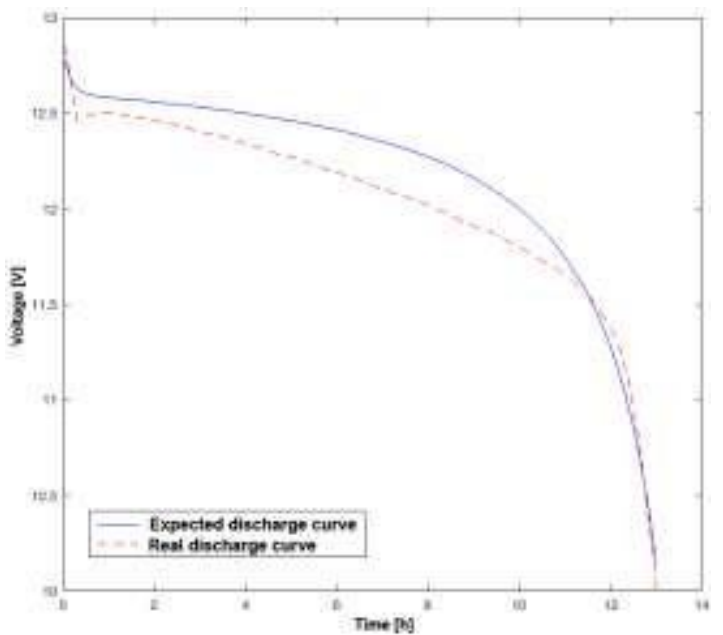

Figure 5: Battery discharge curve with estimated Vnom parameter equal to the voltage in 10 hours

Table 4: Mean squared error and processing time of interpolated information with ten polynomial degree

\begin{tabular}{|c|c|c|}
\hline $\begin{array}{c}\text { Interpolation } \\
\text { Degree }\end{array}$ & MSE & $\begin{array}{c}\text { Processing } \\
\text { Time }\end{array}$ \\
\hline st $^{\text {st }}$ & 0.016345432214655 & 0.001354 \\
\hline $2^{\text {nd }}$ & 0.007852754377196 & 0.002385 \\
\hline $3^{\text {rd }}$ & 0.004025711037217 & 0.003159 \\
\hline $4^{\text {th }}$ & 0.001798383822632 & 0.003443 \\
\hline sth $^{\text {th }}$ & 0.000534896578389 & 0.003694 \\
\hline s $^{\text {th }}$ & 0.000205453491198 & 0.003846 \\
\hline $7^{\text {th }}$ & 0.000008947346863 & 0.003977 \\
\hline s $^{\text {th }}$ & 0.000007123782517 & 0.004166 \\
\hline $9^{\text {th }}$ & 0.000001825118711 & 0.005119 \\
\hline 1 $^{\text {th }}$ & 0.000001522863254 & 0.005538 \\
\hline
\end{tabular}

The interpolated curve that best fits the original curve is the 7th degree polynomial interpolation, considering the mean square error and the simulation time between the interpolated degrees. The choice is based on the fact that the error in the same order of magnitude does not exceed $0.004 \mathrm{~s}$ at the processing time, so that the computational cost does not become high. 


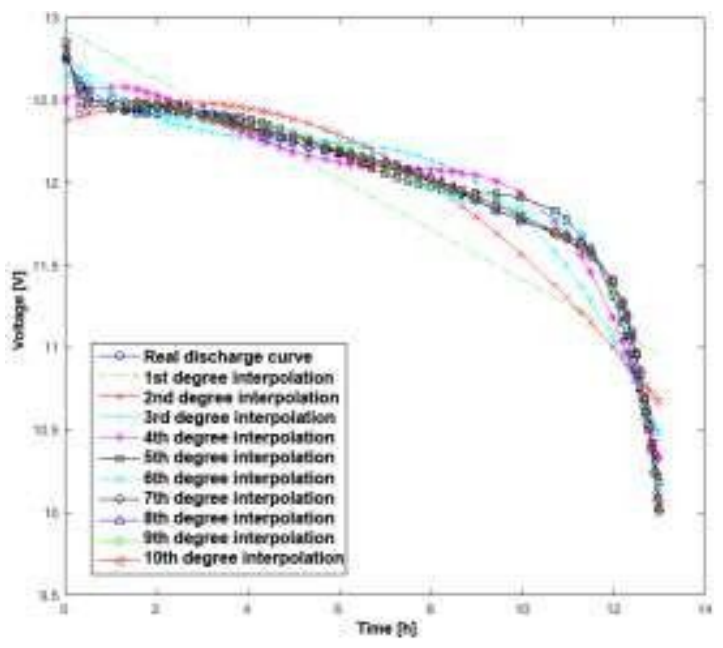

Figure 6: Ten-degree polynomial interpolation of the original curve of the commercial battery

\section{RESULTS}

With the actual battery curve the 7 th degree of interpolation was chosen because there is a processing time that does not exceed $0.004 \mathrm{~s}$. Since its MSE is smaller compared to the original curve, it compensates for its longer processing time. Figure 8 shows the interpolation chosen and can be used to estimate the discharge curve, considering the values of voltage, time and capacity with better performance compared to the curve of the equation.

The values of processing time and MSE of the same are present in Table 5.

The error corresponding to the 7 th degree interpolated is shown in Figure 9.

\section{CONCLUSIONS}

The choice of the third point was made for 10 hours due to the proximity of the discharge curves that were observed. In the same way, but also considering the processing time, the polynomial degree was chosen for the polynomial interpolation, and thus it was possible to compare the curves. By comparing the three curves obtained in Figure 8 , the processing time and the mean square error, it can be stated that the curve obtained with the 7 th degree interpolation was more efficient than the equations defined by Tremblay et al. (2007), but it has the processing time greater than the curve of the equation, which implies computational costs.

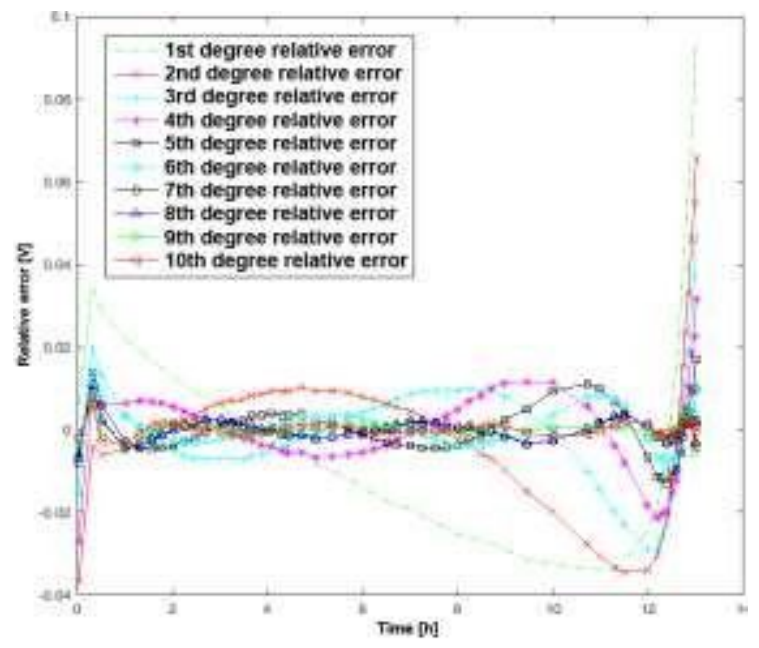

Figure 7: Error for each interpolation of the ten polynomial degree

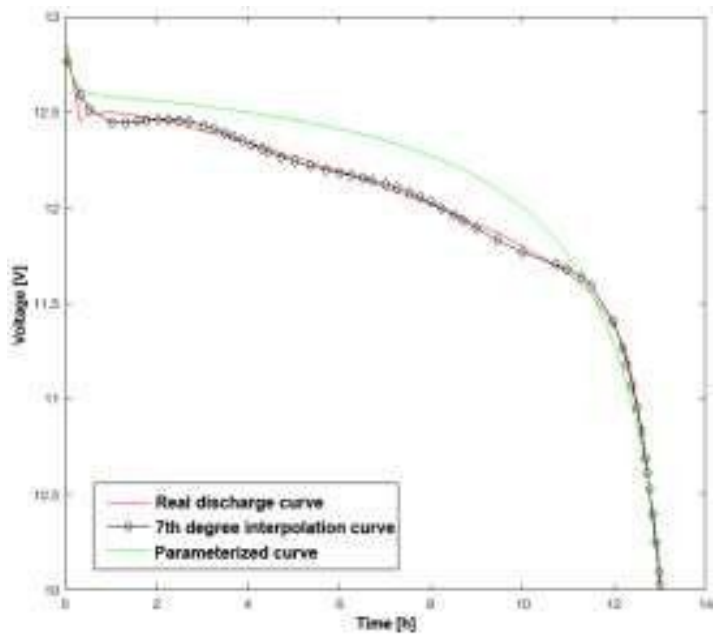

Figure 8: Polynomial interpolated curve with the nominal voltage of $10^{\text {th }}$, curve parameterized as in the model of Tremblay et al. (2007) and the commercial battery discharge curve

Table 5: Comparative MSE values and processing time between the equation and the $7^{\text {th }}$ degree interpolation

\begin{tabular}{|c|c|c|}
\hline Method & MSE & $\begin{array}{c}\text { Processing } \\
\text { Time }\end{array}$ \\
\hline Tremblay & 0.058512658227848 & 0.000045 \\
\hline Interpolation & 0.000008947346863 & 0.003977 \\
\hline
\end{tabular}




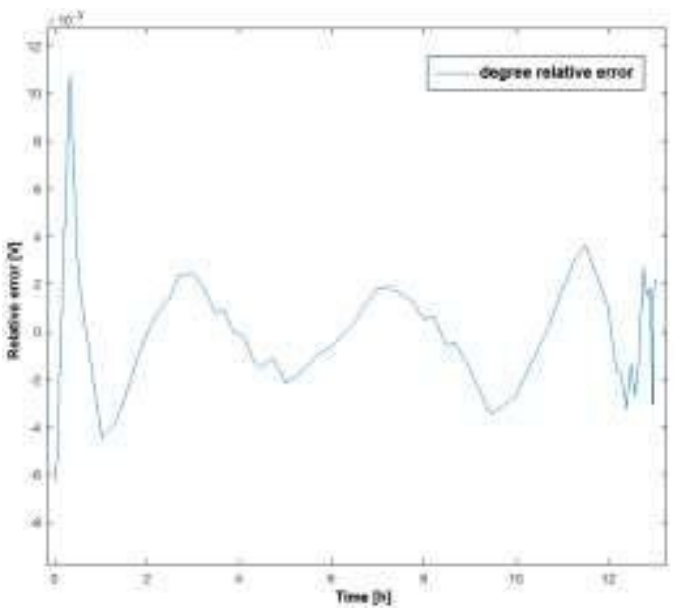

Figure 9: Relative error between the real curve and the curve after the $7^{\text {th }}$ degree interpolation

\section{REFERENCES}

[1] Schmidt C. A. J., Lima M. A. M., A Demanda por Energia Elétrica no Brasil, Rev. Bras. Econ., vol. 58, n 1, Rio de Janeiro, 2004.

[2] Leão J., Hartmann L., Correa M., Lima, A. M. N., Lead-acid Battery Modeling and State of Charge Monitoring, Conf Rec IEEE/APEC, pp. 239-243, 2010.

[3] Bocchi N., Ferracin L. C., Biaggio S. R. Pilha e Bateria: Funcionamento e Impacto Ambiental.Química e Sociedade, vol. 11, pp. 3-9, 2000.

[4] Schneider K. K., Modelos Analíticos na Predição do Tempo de Vida de Baterias Utilizadas em Dispositivos Móveis, Universidade Regional do Noroeste do Estado do Rio Grande do Sul, Brazil, 2011.

[5] Sousa, J. R. B., Modelagem e Supervisão de Bancos de Baterias em Sistemas Múltiplas Fontes de Energia Utilizando Redes de Petri, Dissertação de Mestrado UFCG 2008, vol. 1, 2008.

[6] Bindner H., Cronin T., Lundsager P., Manwell J. F., Abdulwahid U., Baring-Gould I. Lifetime modeling of lead acid batteries, Ris $\varnothing$ DTU National Laboratory for SustainableEnergy, 2005.

[7] Liaw, B. Y., Bethune K. P., Yang X. G. Advanced integrated battery testing and simulation, Journal of Power Sources, vol. 110, pp. 330- 340, 2002.

https://doi.org/10.1016/S0378-7753(02)00195-7

[8] Jackey R. A simple, effective lead-acid battery modeling process for electrical system component selection, Conf Rec SAE World Congress, pp. 1-9, 2007.

https://doi.org/10.4271/2007-01-0778
[9] Durr M., Cruden A., Gair S., McDonald J. R. Dynamic model of a lead acid battery for use in a domestic fuel cell system, Journal of Power Sources, vol. 161, n. 2, pp. 1400-1411, 2006. https://doi.org/10.1016/j.jpowsour.2005.12.075

[10] Ceraolo M., New dynamical models of lead-acid batteries, IEEE Transactions on Power Systems, vol. 15, n. 4, pp. 11841190, nov., 2000. https://doi.org/10.1109/59.898088

[11] Kaiser R., Wenz H., Baring-Gould I., Wilmot N., Mattera F., Nieuwenhout F., Rodrigues C., Perujo A., Rudell A., Lundsager P., Bindner H. Svoboda V. Development of battery lifetime models for energy storage systems in renewable energy systems, Conf. Rec. STORE, pp. 1-6, oct., 2003.

[12] Schiffer J., Sauer D. U., Bindner H., Cronin T., Lundsager P., Kaiser R. Model prediction for ranking lead-acid batteries according to expected lifetime in renewable energy systems and autonomous power-supply systems, Journal of Power Sources, vol. 168 pp. 66- 78, 2007. https://doi.org/10.1016/j.jpowsour.2006.11.092

[13] Shepherd C. Theoretical design of primary and secundary cells - part III - battery dis-charge equation, Technical Report, US, Naval Research Laboratory, 1963.

[14] Tremblay O. and Dessaint L.-A. Experimental validation of a battery dynamics model for EV applications, World Electric Vehicle Journal, vol. 3, pp. 1184-1190, 2009. https://doi.org/10.3390/wevj3020289

[15] Tremblay O., Dessaint L.-A. and Dekkiche A.-I. A generic battery model for the dynamic simulation of hybrid electric vehicles, Conf. Rec. IEEE/VPPC, pp. 284-289, 2007.

[16] Freitas D. C. C., Contribuições à estimativa das características elétricas e ao tempo de vida útil de baterias de chumbo-ácido, Dissertação de Mestrado, UFCG, 2016.

[17] Freitas D. C. C.; Lima A. M. N.; H. S. Silva; Morais M. R. A. Otimização da escolha dos pontos de medição usados na estimação de parâmetros de modelos de baterias de chumboÁcido. Simpósio Brasileiro de Automação Inteligente SBAI, 2015. 